\title{
Growth Responses of Red-Leaf Lettuce to Temporal Spectral Changes
}

\author{
Qingwu Meng ${ }^{\dagger}$ and Erik S. Runkle* \\ Controlled-Environment Lighting Laboratory, Department of Horticulture, Michigan State University, East Lansing, MI, \\ United States
}

\section{OPEN ACCESS}

Edited by:

Eiji Goto,

Chiba University, Japan

Reviewed by:

Roberta Paradiso,

University of Naples Federico II, Italy

Elizabeth Van Volkenburgh,

University of Washington,

United States

${ }^{*}$ Correspondence:

Erik S. Runkle

runkleer@msu.edu

${ }^{\dagger}$ Present address:

Qingwu Meng,

Department of Plant and Soil

Sciences, University of Delaware,

Newark, $D E$, United States

Specialty section:

This article was submitted to Crop and Product Physiology,

a section of the journal

Frontiers in Plant Science

Received: 11 June 2020

Accepted: 30 September 2020

Published: 22 October 2020

Citation:

Meng Q and Runkle ES (2020)

Growth Responses of Red-Leaf

Lettuce to Temporal Spectral

Changes.

Front. Plant Sci. 11:571788

doi: 10.3389/fp/s.2020.571788
Lighting is typically static for indoor production of leafy greens. However, temporal spectrum differentiation for distinct growth phases can potentially control age-specific desirable traits. Spectral effects can be persistent yet dynamic as plants mature, necessitating characterization of time-dependent responses. We grew red-leaf lettuce (Lactuca sativa L.) "Rouxai" in a growth room at $23^{\circ} \mathrm{C}$ and under a $20-\mathrm{h}$ photoperiod created by warm-white (WW), blue (B; peak $=449 \mathrm{~nm})$, green (G; peak $=526 \mathrm{~nm})$, red $(\mathrm{R}$; peak $=664 \mathrm{~nm})$, and/or far-red (FR; peak $=733 \mathrm{~nm})$ light-emitting diodes. From day 0 to 11, plants received six static lighting treatments with the same total photon flux density (400-800 nm): $W W_{180}, R_{180}, B_{20} R_{160}, B_{20} G_{60} R_{100}, B_{20} R_{100} F R_{60}$, or $B_{180}$ (subscripts denote photon flux densities in $\mu \mathrm{mol} \cdot \mathrm{m}^{-2} \cdot \mathrm{s}^{-1}$ ). On day 11, plants grown under each of the six treatments were transferred to all treatments, which created 36 temporal spectrum alternations. Plant growth, morphology, and coloration were measured on days 11 and 25 . Increasing $B$ radiation from 0 to $100 \%$ in static treatments decreased shoot fresh and dry weights and increased foliage redness of seedlings and mature plants. Compared to $B_{20} R_{160}, B_{20} R_{100} F R_{60}$ increased shoot fresh weight, but not dry weight, on both days. However, other phenotypic responses under static treatments changed over time. For example, leaf length under $\mathrm{B}_{180}$ was $35 \%$ lower on day 11 but similar on day 25 compared to that under $R_{180}$. In the $B_{20}$ background, substituting $G_{60}$ for $R$ radiation did not influence shoot weight on day 11 but decreased it by $19 \%$ on day 25 . When plants were switched from one treatment to another on day 11 , the treatments applied before day 11 influenced final shoot weight and, to a lesser extent, leaf length and foliage coloration on day 25. In comparison, effects of the treatments applied after day 11 were more pronounced. We conclude some phenotypic responses to light quality depend on time and sequential light quality treatments had cumulative effects on lettuce growth. The temporal complexity of spectral responses is critical in photobiological research and creates opportunities for time-specific spectrum delivery to optimize crop characteristics.

Keywords: controlled environment, dynamic lighting, LEDs, light quality, morphology, plant growth 


\section{INTRODUCTION}

The spectral composition of lighting in controlled environments can regulate a wide range of commercially relevant crop traits such as harvestable yield, morphology, coloration, and nutritional quality (Carvalho and Folta, 2014a). Red (R; 600$700 \mathrm{~nm}$ ) radiation is typically more effective at stimulating extension growth and biomass accumulation of leafy greens than blue (B; 400-500 nm) or $\mathrm{B}+\mathrm{R}$ radiation (OhashiKaneko et al., 2007; Son and Oh, 2013; Lee et al., 2014). In contrast, $\mathrm{B}$ radiation generally suppresses extension growth (Cope et al., 2014; Wollaeger and Runkle, 2014) but stimulates production of bioactive compounds (Son and Oh, 2013; Lee et al., 2014; Kopsell et al., 2015). Green (G; 500$600 \mathrm{~nm}$ ) radiation penetrates deep in the leaf and crop canopy to promote photosynthesis (Terashima et al., 2009; Brodersen and Vogelmann, 2010). Far-red (FR; 700-800 nm) radiation can induce shade-avoidance symptoms (Cerdán and Chory, 2003; Meng and Runkle, 2019) and regulate anthocyanin production (Carvalho and Folta, 2014b). The combined effects of these wavebands on plant growth and development are often complicated by synergistic or antagonistic interactions. Characterization of these spectral effects on various edible crops has been advanced by research with adjustable arrays of multicolored light-emitting diodes (LEDs) in controlled environments.

Electric lighting is substituted for sunlight to provide photosynthetically active photons for indoor-grown leafy greens. It is generally static throughout the production cycle, whereas field-grown plants undergo fluctuations in light quality, intensity, and duration throughout the day and production cycle. Static lighting feeds constant energy to light-harvesting antennae of photosystem II and maintains steady electron transport and proton generation to produce NADPH and ATP, respectively, which are used in carbon fixation (Armbruster et al., 2014). In contrast, the dynamic nature of sunlight necessitates responsive and efficient photosynthetic acclimation through regulation of energy channeling and dissipation to maintain high photosynthetic efficiency (Demmig-Adams et al., 2012). In arabidopsis [Arabidopsis thaliana (L.) Heynh.], $\mathrm{K}^{+}$efflux antiporter 3 mediated $\mathrm{H}^{+} / \mathrm{K}^{+}$antiport to facilitate rapid restoration of photosystem II quantum efficiency after plants were transferred from high to low light or from darkness to low light (Armbruster et al., 2014). Such mechanisms allow plants to thrive in continuously changing light environments.

Switching from static to dynamic lighting for indoor crop production adds the temporal factor in crop responses to improve crop traits. Temporal spectrum differentiation can occur in large or small segments of the crop life cycle to elicit age-dependent, desirable attributes. For example, anthocyanin accumulation in red-leaf lettuce (Lactuca sativa $\mathrm{L}$.) is unnecessary for seedlings but desirable for mature plants at harvest. It can be induced rapidly by $\geq 4$ days of end-of-production supplemental lighting from B and/or R LEDs (Owen and Lopez, 2015; Gómez and Jiménez, 2020). In addition, $\mathrm{R}$ radiation induced excessive extension growth of lettuce "Crispa" seedlings but increased dry weight of mature plants compared to B or B $+\mathrm{R}$ radiation (Chen et al., 2014). Therefore, it could be potentially beneficial to produce compact seedlings under $\mathrm{B}$ or $\mathrm{B}+\mathrm{R}$ radiation and then switch to $\mathrm{R}$ radiation to promote growth of mature plants. After the seedling phase, weekly progressive spectrum alternations of $\mathrm{B}$ and/or $\mathrm{R}$ radiation influenced shoot growth, morphology, and phytochemical accumulation of lettuce "Sunmang" (Son et al., 2017). A greater dose of B radiation increased secondary metabolite concentrations, whereas a greater dose of $\mathrm{R}$ radiation increased shoot weight and projected leaf area (Son et al., 2017). Changing the spectrum in shorter periods of plant development can also modulate final crop phenotypes. For example, 4-day sequential B, R, and/or FR lighting treatments influenced stem elongation, anthocyanin concentration, and antioxidant capacity of kale (Brassica napus L. var. sabellica) seedlings, showing strong plant plasticity in response to spectral changes (Carvalho and Folta, 2014b). Furthermore, staggering $\mathrm{B}$ and $\mathrm{R}$ radiation within the day increased shoot weight of romaine lettuce (Lactuca sativa $\mathrm{L}$. var. longifolia) compared to simultaneous $\mathrm{B}+\mathrm{R}$ radiation (Jishi et al., 2016).

Under changing light conditions, a light response can be transient or persistent. Examples of a transient light response include stomatal opening and phototropism under B radiation as well as increasing net photosynthesis with incremental increases in photon flux densities. These rapid responses are reversible after the light condition changes. On the other hand, a spectrum applied in an early developmental phase can have persistent and irreversible influence on subsequent phenotypic responses. For example, the addition of FR radiation to $\mathrm{B}+\mathrm{R}$ radiation during seedling development of snapdragon (Antirrhinum majus L.) promoted flowering when plants were finished in a greenhouse environment (Park and Runkle, 2017). In addition, B or $\mathrm{R}$ radiation applied for 7 days after emergence influenced leaf area and shoot dry weight of lettuce "Grand Rapids" 16 or 42 days after emergence, irrespective of a switch to the opposite waveband on day 7 (Eskins et al., 1995). However, such sustained spectral effects were not observed in other lettuce studies with a fixed spectrum early in seeding development and varying spectra afterward (Johkan et al., 2010; Son and Oh, 2013). Furthermore, the influence of a spectrum on lettuce growth and morphology can vary with each developmental phase. For example, when applied day 10-17 after seed sow, B radiation decreased leaf area and shoot fresh weight of lettuce "Banchu Red Fire" on day 17 but increased them on day 45 compared to $\mathrm{R}$ radiation (Johkan et al., 2010). The discrepancies in these studies likely result from different genetic backgrounds, light intensities, and spectral contexts.

Here, we expanded static spectral combinations to include G, FR, and warm-white (WW) radiation and created a wide array of lighting treatments shifted temporally between the seedling and mature phases of indoor lettuce production. The objectives of this study were (1) to investigate how spectral treatments for lettuce seedlings influence phenotypes of mature plants grown under different spectra; (2) to compare lettuce growth under single wavebands, combinations of two or three wavebands, and WW radiation; and (3) to find temporal spectral combinations 
for desirable lettuce growth and morphology. We postulated that (1) the spectral effects during the seedling stage would persist through the mature phase, regardless of the finishing spectral environment; (2) substituting $\mathrm{G}$ radiation for $\mathrm{R}$ radiation would increase lettuce growth during the seedling stage but have little influence on growth of mature plants; and (3) B radiation alone would inhibit leaf expansion and dry weight during the seedling phase but promote them during the mature phase.

\section{MATERIALS AND METHODS}

\section{The Propagation Phase}

This experiment was performed in a refrigerated walk-in growth room of the Controlled-Environment Lighting Laboratory (Michigan State University, East Lansing, MI). We chose lettuce to study because it is the most widely grown hydroponic crop in indoor vertical farms for its short stature, fast growth rate, and high value. Our previous studies showed generally similar growth responses of green- and red-leaf lettuce, so we studied redleaf lettuce because of its unique foliage coloration in response to spectral alternations (Meng and Runkle, 2019; Meng et al., 2019). Seeds of red oakleaf lettuce "Rouxai" were obtained from a commercial seed producer (Johnny's Selected Seeds, Winslow, ME, United States) and sown in a rockwool substrate with 200 2.5-cm-wide cubes per sheet (AO 25/40 Starter Plugs; Grodan, Milton, ON, Canada) on April 28 and 29, 2018 for two blocks. The substrate was presoaked in deionized water supplemented with diluted (1:31) 95-98\% sulfuric acid (J.Y. Baker, Inc., Phillipsburg, NJ, United States), a water-soluble fertilizer (12N$4 \mathrm{P}_{2} \mathrm{O}_{5}-16 \mathrm{~K}_{2} \mathrm{O}$ RO Hydro FeED; JR Peters, Inc., Allentown, PA, United States), and magnesium sulfate (Epsom salt; Pennington Seed, Inc., Madison, GA, United States) to achieve a $\mathrm{pH}$ of 3.9 and an electrical conductivity of $1.6 \mathrm{mS} \cdot \mathrm{cm}^{-1}$. The nutrient solution contained the following nutrients (in $\mathrm{mg} \cdot \mathrm{L}^{-1}$ ): $125 \mathrm{~N}$, $42 \mathrm{P}, 167 \mathrm{~K}, 73 \mathrm{Ca}, 49 \mathrm{Mg}, 39 \mathrm{~S}, 1.7 \mathrm{Fe}, 0.52 \mathrm{Mn}, 0.56 \mathrm{Zn}$, $0.13 \mathrm{~B}, 0.47 \mathrm{Cu}$, and $0.13 \mathrm{Mo}$. Seed trays were covered with transparent humidity domes and placed under six different lighting treatments, each at a total photon flux density (TPFD; 400-800 $\mathrm{nm}$ ) of $180 \mu \mathrm{mol} \cdot \mathrm{m}^{-2} \cdot \mathrm{s}^{-1}$ with a 20 -h photoperiod. Air temperature was set at $20^{\circ} \mathrm{C}$ from April 28 to 30, 2018 and increased to $23^{\circ} \mathrm{C}$ for the remainder of the experiment. From day 1 to 11 , seedlings were subirrigated as needed using the same nutrient solution with a $\mathrm{pH}$ of 5.8 adjusted with potassium bicarbonate. The humidity domes were removed on May 3, 2018 for both blocks.

\section{The Production Phase}

On day 11, when the second true leaf was expanding, seedlings in rockwool cubes were transplanted into 36-cell rafts (36 2.5-cm-wide holes on each lightweight raft measuring $60.9 \mathrm{~cm} \times 121.9 \mathrm{~cm} \times 2.5 \mathrm{~cm}$; Beaver Plastics, Ltd., Acheson, $\mathrm{AB}$, Canada) floating in flood tables $(1.22 \mathrm{~m} \times 0.61 \mathrm{~m} \times 0.18 \mathrm{~m}$; Active Aqua AAHR24W; Hydrofarm, Petaluma, CA, United States) on three-tier racks (Indoor Harvest, Houston, TX, United States). Plants were spaced $20 \mathrm{~cm}$ apart horizontally and $15 \mathrm{~cm}$ apart diagonally. The recirculating nutrient solution was mixed as described for seedlings to provide the following nutrients (in $\mathrm{mg} \cdot \mathrm{L}^{-1}$ ): $150 \mathrm{~N}, 50 \mathrm{P}, 200 \mathrm{~K}, 88 \mathrm{Ca}, 58 \mathrm{Mg}, 47 \mathrm{~S}$, 2.1 Fe, $0.63 \mathrm{Mn}, 0.68 \mathrm{Zn}, 0.15 \mathrm{~B}, 0.56 \mathrm{Cu}$, and $0.15 \mathrm{Mo}$. It was oxygenated with a circular air stone $(20.3 \times 2.5 \mathrm{~cm}$; Active Aqua AS8RD; Hydrofarm) connected to a $60-\mathrm{W}$ air pump (Active Aqua AAPA70L; Hydrofarm). The $\mathrm{pH}$, electrical conductivity, and temperature of the nutrient solution for each lighting canopy were measured daily using a portable $\mathrm{pH}$ and electrical conductivity meter (HI9814; Hanna Instruments, Woonsocket, RI, United States) (Table 1). Potassium bicarbonate was used to increase $\mathrm{pH}$ when it dropped below 5.5 .

\section{Environmental Conditions}

Temperature in the growth room was regulated with an industrial ventilation and air-conditioning unit (HBH030A3C20CRS; Heat Controller, LLC., Jackson, MI, United States) connected to a wireless thermostat (Honeywell International, Inc., Morris Plains, NJ, United States). The deep-flow hydroponic system was equipped with two light quantum sensors (LI-190R; LI-COR, Inc., Lincoln, NE, United States), two thermocouples (0.13-mm type E; Omega Engineering, Inc., Stamford, CT, United States), two infrared sensors (OS36-01-K-80F; Omega Engineering, Inc.), a $\mathrm{CO}_{2}$ transmitter (GMD20; Vaisala, Inc., Louisville, $\mathrm{CO}$, United States), and a relative humidity and temperature probe (HMP110; Vaisala, Inc.). All sensors were connected to a datalogger (CR1000; Campbell Scientific, Inc., Logan, UT, United States) with a multiplexer (AM16/32B; Campbell Scientific, Inc.), which recorded environmental parameters every $10 \mathrm{~s}$ and logged hourly averages using computer software (LoggerNet; Campbell Scientific, Inc.). The air temperature, canopy temperature, $\mathrm{CO}_{2}$ concentration, and relatively humidity throughout the experiment (mean \pm standard deviation) were $22.5 \pm 1.0^{\circ} \mathrm{C}, 24.1 \pm 0.9^{\circ} \mathrm{C}, 392 \pm 31 \mathrm{ppm}$, and $44 \pm 8 \%$, respectively.

\section{Lighting Treatments}

Seedlings were grown under $\mathrm{WW}_{180}, \mathrm{R}_{180}, \mathrm{~B}_{20} \mathrm{R}_{160}, \mathrm{~B}_{20} \mathrm{G}_{60} \mathrm{R}_{100}$, $\mathrm{B}_{20} \mathrm{R}_{100} \mathrm{FR}_{60}$, or $\mathrm{B}_{180}$ LEDs (PHYTOFY RL; OSRAM, Beverley, MA, United States), where the subscript following each LED type indicates its photon flux density (in $\mu \mathrm{mol} \cdot \mathrm{m}^{-2} \cdot \mathrm{s}^{-1}$ ). The peak wavelengths of WW, B, G, R, and FR LEDs were $639,449,526,664$, and $733 \mathrm{~nm}$, respectively. The outputs of seven color channels, including five used in this study, in each LED fixture were independently controlled with software (Spartan Control Software; OSRAM). The specifications, layout, and positioning of the LED fixtures were as described by Meng et al. (2019). Spectra were measured at seven locations at plant canopy of each lighting treatment using a portable spectroradiometer (PS200; Apogee Instruments, Inc., Logan, UT, United States) (Figure 1). The single-band photon flux densities, photosynthetic photon flux density (PPFD; 400-700 nm), TPFD, yield photon flux density [YPFD, an integrated value based on relative quantum efficiency (McCree, 1972) and spectral data], phytochrome photoequilibrium [PPE, an estimated value based on phytochrome absorption coefficients and spectra data (Sager et al., 1988)], ratio of $B$ to $R$ radiation (B:R), and ratio of $R$ to FR radiation (R:FR) for each lighting treatment were subsequently 
TABLE 1 | The $\mathrm{pH}$, electrical conductivity, and water temperature (mean \pm standard deviation) of nutrient solutions for six lighting treatment plots in two blocks during the lettuce production phase.

\begin{tabular}{|c|c|c|c|c|c|c|}
\hline \multirow[t]{2}{*}{ Lighting treatment } & \multicolumn{2}{|c|}{$\mathrm{pH}$} & \multicolumn{2}{|c|}{ Electrical conductivity $\left(\mathrm{mS} \cdot \mathrm{cm}^{-1}\right)$} & \multicolumn{2}{|c|}{ Water temperature $\left({ }^{\circ} \mathrm{C}\right)$} \\
\hline & Block 1 & Block 2 & Block 1 & Block 2 & Block 1 & Block 2 \\
\hline $\mathrm{WW}_{180}$ & $6.0 \pm 1.0$ & $6.2 \pm 0.9$ & $1.8 \pm 0.0$ & $1.8 \pm 0.1$ & $23.7 \pm 0.3$ & $23.3 \pm 0.3$ \\
\hline $\mathrm{R}_{180}$ & $6.1 \pm 1.0$ & $6.3 \pm 0.9$ & $1.9 \pm 0.1$ & $1.7 \pm 0.1$ & $22.9 \pm 0.2$ & $23.9 \pm 0.4$ \\
\hline $\mathrm{B}_{20} \mathrm{R}_{160}$ & $6.1 \pm 1.0$ & $6.3 \pm 0.9$ & $1.9 \pm 0.1$ & $1.7 \pm 0.1$ & $22.9 \pm 0.2$ & $23.9 \pm 0.4$ \\
\hline $\mathrm{B}_{20} \mathrm{G}_{60} \mathrm{R}_{100}$ & $6.1 \pm 1.0$ & $6.3 \pm 0.9$ & $1.9 \pm 0.1$ & $1.7 \pm 0.1$ & $22.9 \pm 0.2$ & $23.9 \pm 0.4$ \\
\hline $\mathrm{B}_{20} \mathrm{R}_{100} \mathrm{FR}_{60}$ & $6.0 \pm 1.0$ & $6.2 \pm 0.9$ & $1.8 \pm 0.0$ & $1.8 \pm 0.1$ & $23.7 \pm 0.3$ & $23.3 \pm 0.3$ \\
\hline $\mathrm{B}_{180}$ & $6.0 \pm 1.0$ & $6.2 \pm 0.9$ & $1.8 \pm 0.0$ & $1.8 \pm 0.1$ & $23.7 \pm 0.3$ & $23.3 \pm 0.3$ \\
\hline
\end{tabular}

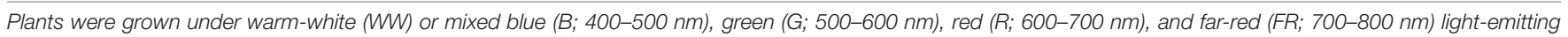
diodes (LEDs). The number following each LED type is its respective photon flux density in $\mu \mathrm{mol} \cdot \mathrm{m}^{-2} \cdot \mathrm{s}^{-1}$.

calculated (Table 2). To study the temporal effects of light quality, lighting treatments were switched between the propagation phase (day 0-11) and the production phase (day 11-25). Seedlings grown under each of the six lighting treatments were transferred to all six lighting treatments on day 11 . This created a total of 36 unique temporal lighting combinations, six of which were static (without transfers) throughout the experiment (Table 3).

\section{Data Collection and Analysis}

Shoot fresh and dry weights, leaf morphology, and coloration data were collected on ten young lettuce plants per block grown under each of the six static lighting treatments on day 11 and on eight mature lettuce plants per block grown under each of the 36 temporal lighting combinations on day 25. Shoot fresh weight was measured with an analytical balance (GR200; A\&D Store, Inc., Wood Dale, IL, United States) for young plants and a different one (GX-1000; A\&D Store, Inc.) for mature plants based on capacities. Length of the fifth most mature true leaf was measured to quantify extension growth. The International Commission on Illumination Lab color space analysis was conducted on a representative leaf per plant using a colorimeter (Chroma Meter CR-400; Konica Minolta Sensing, Inc.). $L^{*}, a^{*}$, and $b^{*}$ indicate foliage brightness (ranging from 0 for black to 100 for diffuse white), greenness-redness (corresponding to negative-positive directions), and bluenessyellowness (corresponding to negative-positive directions), respectively. Subsequently, plants were dried in an oven (Blue $\mathrm{M}$, Blue Island, IL) at $60^{\circ} \mathrm{C}$ for $\geq 5$ days followed by dry weight measurements with the same analytical balances as for shoot fresh weight.

Data on young and mature lettuce plants were analyzed with the PROC MIXED procedure and Tukey's honestly significant difference test $(\alpha=0.05)$ in SAS (version 9.4; SAS Institute, Inc., Cary, NC, United States). Data from static treatments were analyzed as a randomized complete block design with two blocks (using opposite racks of the growth room), six static lighting treatments, and subsampling $(n=10)$, assuming fixed block effects. Data from alternate treatments were analyzed as a stripsplit-plot design with two blocks, six whole-plot levels (posttransplant lighting treatments), six subplot levels (pre-transplant lighting treatments), and subsampling $(n=8)$, assuming fixed block effects. The split-plot design included whole plots arranged in a randomized complete block design.

\section{RESULTS}

\section{Static Lighting Treatments for Young and Mature Lettuce}

On day 11, shoot fresh weight was $40-44 \%$ lower, and shoot dry weight was $39-42 \%$ lower, under $\mathrm{B}_{180}$ than under $\mathrm{WW}_{180}$ and $\mathrm{R}_{180}$ (Figure 2A). Partial substitution of $\mathrm{R}$ radiation in $\mathrm{B}_{20} \mathrm{R}_{160}$ with $60 \mu \mathrm{mol} \cdot \mathrm{m}^{-2} \cdot \mathrm{s}^{-1}$ of $\mathrm{G}$ radiation $\left(\mathrm{B}_{20} \mathrm{G}_{60} \mathrm{R}_{100}\right)$ or FR radiation $\left(B_{20} R_{100} F_{60}\right)$ did not influence shoot dry weight, whereas the substitution with FR radiation increased shoot fresh weight by $18 \%$. Substituting $20 \mu \mathrm{mol} \cdot \mathrm{m}^{-2} \cdot \mathrm{s}^{-1}$ of B radiation for $R$ radiation $\left(B_{20} R_{160}\right.$ versus $\left.R_{180}\right)$ decreased shoot dry weight by $15 \%$, but not shoot fresh weight. On day 25 , increasing substitution of $\mathrm{R}$ radiation with $\mathrm{B}$ radiation decreased shoot fresh and dry weights (Figure 2B). Shoot fresh weight was 63$65 \%$ lower, and shoot dry weight was 52-57\% lower, under $\mathrm{B}_{180}$ than under $\mathrm{R}_{180}$ or $\mathrm{WW}_{180}$. Substituting $60 \mu \mathrm{mol} \cdot \mathrm{m}^{-2} \cdot \mathrm{s}^{-1}$ of $G$ radiation for $R$ radiation in $B_{20} R_{160}$ decreased shoot fresh and dry weights by $19 \%$. The same substitution with FR radiation increased shoot fresh weight by $22 \%$, but not shoot dry weight.

On day 11 , leaves were the longest under $\mathrm{WW}_{180}, \mathrm{R}_{180}$, and $\mathrm{B}_{20} \mathrm{R}_{100} \mathrm{FR}_{60}$ and the shortest under $\mathrm{B}_{180}$ (Figure 2C). Increasing substitution of $\mathrm{R}$ radiation with $\mathrm{B}$ radiation decreased leaf length. Substituting $60 \mu \mathrm{mol} \cdot \mathrm{m}^{-2} \cdot \mathrm{s}^{-1}$ of $\mathrm{G}$ or FR radiation for $\mathrm{R}$ radiation in $\mathrm{B}_{20} \mathrm{R}_{160}$ increased leaf length by 11 or $42 \%$, respectively. On day 25 , leaves were the longest under $\mathrm{B}_{20} \mathrm{R}_{100} \mathrm{FR}_{60}$ and the shortest under $\mathrm{B}_{20} \mathrm{R}_{160}$ and $\mathrm{B}_{20} \mathrm{G}_{60} \mathrm{R}_{100}$ (Figure 2D). Compared to $\mathrm{WW}_{180}$, leaves were $8 \%$ shorter under $\mathrm{R}_{180}$ and similar under $\mathrm{B}_{180}$. Although substituting $20 \mu \mathrm{mol} \cdot \mathrm{m}^{-2} \cdot \mathrm{s}^{-1}$ of $\mathrm{B}$ radiation for $\mathrm{R}$ radiation decreased leaf length by $11 \%$, leaf length was similar under $\mathrm{R}_{180}$ and $\mathrm{B}_{180}$. Substituting $60 \mu \mathrm{mol} \cdot \mathrm{m}^{-2} \cdot \mathrm{s}^{-1}$ of $\mathrm{FR}$ radiation for $\mathrm{R}$ radiation in $B_{20} R_{160}$ increased leaf length by $41 \%$, but the same substitution with $\mathrm{G}$ radiation did not influence it.

On day 11 , foliage brightness $\left(L^{*}\right)$ was the greatest under $\mathrm{R}_{180}$, followed by $\mathrm{WW}_{180}$ and $\mathrm{B}_{20} \mathrm{R}_{100} \mathrm{FR}_{60}$ (Figure 3A). Adding $\mathrm{B}$ 

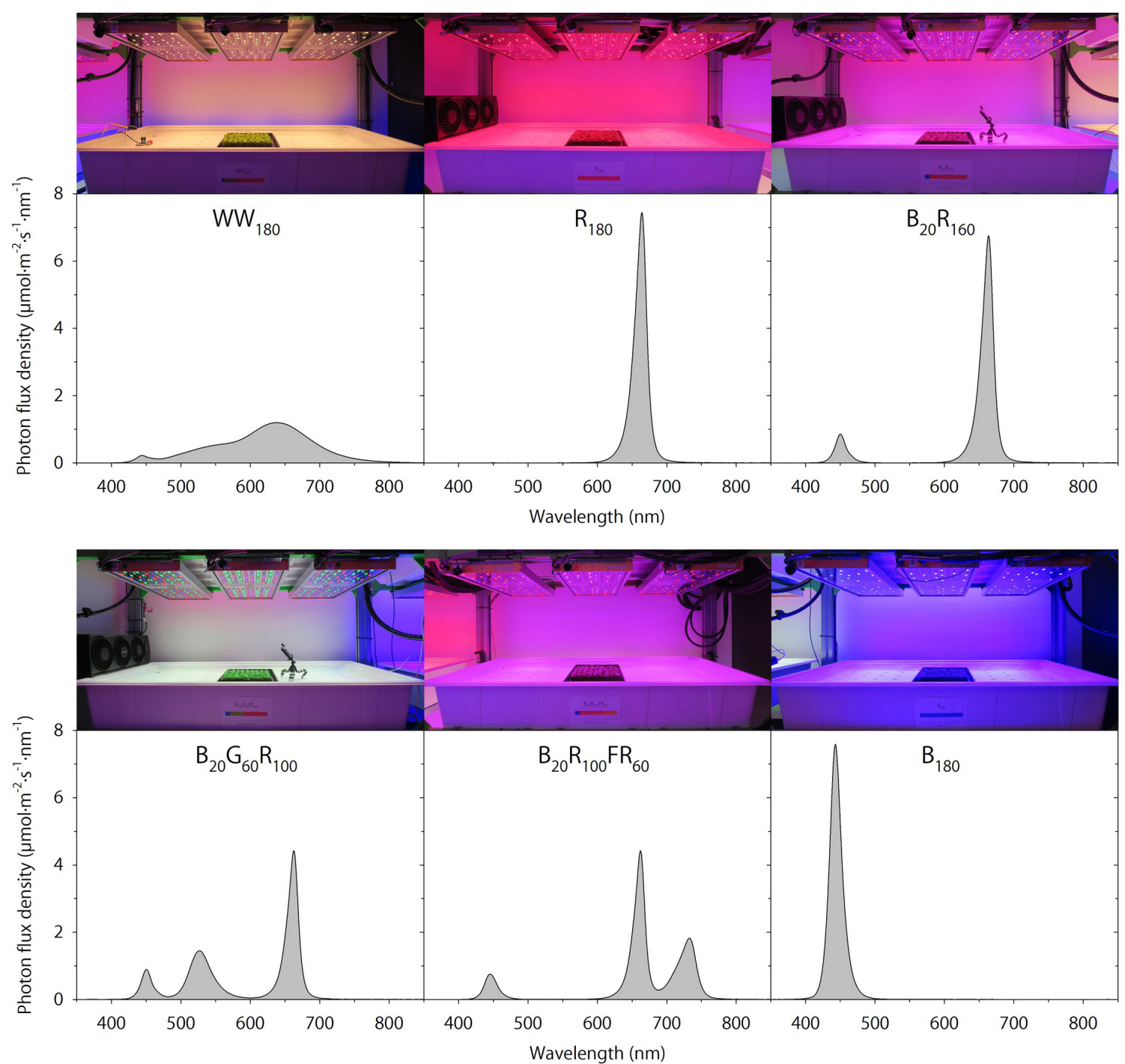

FIGURE 1 | Spectral distributions of six lighting treatments delivered by warm-white (WW) or mixed blue (B; 400-500 nm), green (G; 500-600 nm), red (R; 600-700 nm), and far-red (FR; 700-800 nm) light-emitting diodes (LEDs). The number following each LED type is its respective photon flux density in $\mu \mathrm{mol}^{-\mathrm{m}^{-2}} \cdot \mathrm{s}^{-1}$

radiation to $R_{180}$ decreased brightness. Substituting $R$ radiation in $\mathrm{B}_{20} \mathrm{R}_{160}$ with $\mathrm{G}$ or $\mathrm{FR}$ radiation increased brightness, especially with FR radiation. On day 25 , leaves were the brightest under $\mathrm{R}_{180}$ and $W_{180}$ and the darkest under $B_{180}$ (Figure $3 B$ ). Increasing substitution of $\mathrm{R}$ radiation with $\mathrm{B}$ radiation decreased brightness. Leaves were brighter when $R$ radiation in $B_{20} R_{160}$ was substituted with $\mathrm{FR}$ radiation, but not $\mathrm{G}$ radiation.

On day 11, leaves were the least red (lowest $a^{*}$ ) and yellowest (highest $b^{*}$ ) under $\mathrm{R}_{180}$, followed by $\mathrm{WW}_{180}$ and $\mathrm{B}_{20} \mathrm{R}_{100} \mathrm{FR}_{60}$, and the reddest and least yellow under $\mathrm{B}_{180}$ (Figures $3 \mathrm{C}, \mathrm{E}$ ). The inclusion of $\mathrm{B}$ radiation in an $\mathrm{R}$ background increased redness and decreased yellowness, whereas the inclusion of G or FR radiation decreased redness and increased yellowness. At the same photon flux density, FR radiation reduced redness and increased yellowness more than $\mathrm{G}$ radiation. The $a^{*}$ and $b^{*}$ trends on day 25 were similar to those on day 11 , except that there were no differences between $\mathrm{R}_{180}$ and $\mathrm{WW}_{180}$ or between $\mathrm{B}_{20} \mathrm{G}_{60} \mathrm{R}_{100}$ and $\mathrm{B}_{20} \mathrm{R}_{100} \mathrm{FR}_{60}$ on day 25 (Figures $3 \mathrm{D}, \mathrm{F}$ ).

\section{Temporal Lighting Combinations for Mature Lettuce}

Data on day 25 from 36 temporal lighting combinations are shown in Figure 4. Within each eventual treatment applied day $11-25$, the initial treatments applied day 0-11 significantly influenced final shoot fresh and dry weights and leaf length on day 25 , but not foliage red-green coloration. Irrespective of the eventual treatment, final shoot fresh and dry weights were generally the greatest when plants were initially grown under $W W_{180}, R_{180}$, or $B_{20} R_{100} F_{60}$ and the lowest when initially grown under $\mathrm{B}_{180}$. Responses of final shoot fresh and dry weights to initial treatments $B_{20} R_{160}$ and $B_{20} G_{60} R_{100}$ were variable within 
TABLE 2 | Spectral characteristics of six lighting treatments delivered by warm-white (WW) or mixed blue (B; 400-500 nm), green (G; 500-600 nm), red (R; 600-700 nm), and far-red (FR; 700-800 nm) light-emitting diodes (LEDs).

LED lighting treatment

\begin{tabular}{|c|c|c|c|c|c|c|}
\hline & $W W_{180}$ & $\mathbf{R}_{180}$ & $\mathbf{B}_{20} \mathbf{R}_{160}$ & $B_{20} G_{60} R_{100}$ & $\mathbf{B}_{\mathbf{2 0}} \mathbf{R}_{100} \mathrm{FR}_{60}$ & $\mathbf{B}_{180}$ \\
\hline \multicolumn{7}{|c|}{ Single-band photon flux density $\left(\mu \mathrm{mol} \cdot \mathrm{m}^{-2} \cdot \mathrm{s}^{-1}\right)$} \\
\hline$B$ & 12.5 & 0.3 & 19.2 & 22.9 & 18.8 & 178.4 \\
\hline G & 52.8 & 0.7 & 0.7 & 59.7 & 0.8 & 0.9 \\
\hline $\mathrm{R}$ & 98.1 & 176.9 & 158.5 & 99.4 & 102.2 & 0.5 \\
\hline $\mathrm{FR}$ & 18.1 & 2.1 & 1.9 & 1.3 & 60.7 & 0.1 \\
\hline \multicolumn{7}{|c|}{ Integrated photon flux density $\left(\mu \mathrm{mol} \cdot \mathrm{m}^{-2} \cdot \mathrm{s}^{-1}\right)$} \\
\hline PPFD & 163.3 & 177.9 & 178.4 & 181.9 & 121.8 & 179.7 \\
\hline TPFD & 181.4 & 180.0 & 180.3 & 183.2 & 182.4 & 179.9 \\
\hline YPFD & 149.5 & 165.0 & 162.1 & 156.5 & 119.3 & 134.4 \\
\hline \multicolumn{7}{|c|}{ Radiation ratio } \\
\hline$B: R$ & 0.13 & 0.00 & 0.12 & 0.23 & 0.18 & 386.80 \\
\hline $\mathrm{R}: \mathrm{FR}$ & 5.42 & 83.96 & 82.98 & 76.19 & 1.68 & 3.49 \\
\hline PPE & 0.829 & 0.882 & 0.880 & 0.878 & 0.764 & 0.480 \\
\hline
\end{tabular}

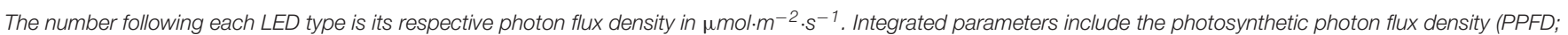

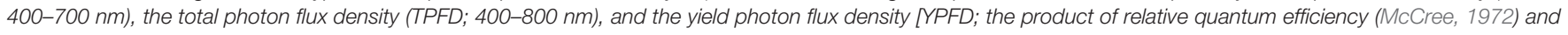
spectral data from 300 to $800 \mathrm{~nm}$ ]. The estimated phytochrome photoequilibrium (PPE) was calculated as described by Sager et al. (1988).

each eventual treatment. Final leaf length within each eventual treatment was mostly similar under initial treatments except $\mathrm{B}_{180}$, under which final leaf length within each eventual treatment was slightly lower than that under some other initial treatments.

\section{The Effects of Initial and Eventual Lighting Treatments on Mature Lettuce}

To dissect the effects of initial (applied day 0-11) and eventual (applied day 11-25) lighting treatments on lettuce harvested on day 25, data of plants grown under the same initial treatments were pooled for initial treatment analysis, whereas data of plants grown under the same eventual treatments were pooled for eventual treatment analysis. The effects of the six lighting treatments on final shoot fresh and weight weights, leaf length, and color parameters were different when applied day 0-11 versus day 11-25 (Figures 5,6).

When the lighting treatments were applied day $0-11$, final shoot fresh and dry weights (on day 25) were the greatest under $\mathrm{WW}_{180}, \mathrm{R}_{180}$, and $\mathrm{B}_{20} \mathrm{R}_{100} \mathrm{FR}_{60}$, followed by $\mathrm{B}_{20} \mathrm{R}_{160}$ and $B_{20} G_{60} R_{100}$, and the lowest under $B_{180}$ (Figure 5A). In addition, final leaf length under $\mathrm{WW}_{180}$ and $\mathrm{R}_{180}$ was slightly greater than that under $\mathrm{B}_{20} \mathrm{R}_{100} \mathrm{FR}_{60}$ and $\mathrm{B}_{180}$ (Figure $5 \mathrm{C}$ ). Leaves were slightly brighter under $B_{20} G_{60} R_{100}$ than under $\mathrm{B}_{180}$, slightly redder under $\mathrm{B}_{20} \mathrm{R}_{160}$ and $\mathrm{B}_{180}$ than under $\mathrm{B}_{20} \mathrm{G}_{60} \mathrm{R}_{100}$, and slightly yellower under $\mathrm{B}_{20} \mathrm{G}_{60} \mathrm{R}_{100}$ than under $\mathrm{B}_{180}$ (Figures 6A,C,E). Otherwise, leaf color parameters were similar under most treatments.

Treatment effects were more pronounced when applied day 11-25. Final shoot fresh and dry weights were the greatest under $\mathrm{R}_{180}$, followed by $\mathrm{WW}_{180}$ and $\mathrm{B}_{20} \mathrm{R}_{100} \mathrm{FR}_{60}$, and the lowest under $\mathrm{B}_{180}$ (Figure 5B). Partially substituting $\mathrm{B}$ radiation for $\mathrm{R}_{180}$ decreased shoot weight. Substituting $60 \mu \mathrm{mol} \cdot \mathrm{m}^{-2} \cdot \mathrm{s}^{-1}$ of $\mathrm{G}$ and $\mathrm{FR}$ radiation for $\mathrm{R}$ radiation in $\mathrm{B}_{20} \mathrm{R}_{160}$ decreased and increased shoot weight, respectively. Final leaf length was the greatest under
$\mathrm{B}_{20} \mathrm{R}_{100} \mathrm{FR}_{60}$, followed by $\mathrm{WW}_{180}$ and $\mathrm{B}_{180}$, and lowest under $\mathrm{B}_{20} \mathrm{R}_{160}$ and $\mathrm{B}_{20} \mathrm{G}_{60} \mathrm{R}_{100}$ (Figure 5D). Leaf length under $\mathrm{R}_{180}$ was between that under $W_{180}$ and $B_{20} R_{160}$. Leaf color was the brightest under $\mathrm{WW}_{180}$ and $\mathrm{R}_{180}$, followed by $\mathrm{B}_{20} \mathrm{R}_{100} \mathrm{FR}_{60}$, and the least bright under $\mathrm{B}_{180}$ (Figure 6B). Leaf brightness under $\mathrm{B}_{20} \mathrm{R}_{160}$ and $\mathrm{B}_{20} \mathrm{G}_{60} \mathrm{R}_{100}$ was between that under $\mathrm{B}_{20} \mathrm{R}_{100} \mathrm{FR}_{60}$ and that under $\mathrm{B}_{180}$. Leaves were the reddest under $\mathrm{B}_{180}$, followed by $B_{20} R_{160}$, and the least red under $R_{180}$, followed by $W_{180}$ (Figure 6D). Compared to $\mathrm{B}_{20} \mathrm{R}_{160}$, leaf redness was reduced with substitutional $\mathrm{G}$ and $\mathrm{FR}$ radiation, especially with the latter. The $b^{*}$ trend was the opposite of the $a^{*}$ trend (Figure $6 \mathbf{F}$ ).

\section{DISCUSSION}

When lettuce "Rouxai" received static lighting throughout this study, phenotypic responses during the propagation and production phases were generally similar but varied under some treatments. On days 11 and 25, increasing $B: R$ decreased shoot fresh and dry weights, increased leaf redness, and decreased leaf brightness and yellowness. In addition, increasing B:R decreased leaf length on day 11 . These results are consistent with the notion that $\mathrm{B}$ radiation generally inhibits extension growth and shoot weight while promoting accumulation of chlorophylls, anthocyanins, and other secondary metabolites (Son and Oh, 2013; Kopsell et al., 2015; Wollaeger and Runkle, 2015). However, compared to $\mathrm{R}_{180}$, leaf length on day 25 was lower under $\mathrm{B}_{20} \mathrm{R}_{160}$ but similar under $\mathrm{B}_{180}$. Aberrant promotion of extension growth and weight gain by $\mathrm{B}$ radiation alone was previously observed in cucumber (Cucumis sativus L.) and cherry tomato (Solanum lycopersicum L. var. cerasiforme) seedlings and lettuce "Grand Rapids" (Eskins et al., 1995; Liu et al., 2009; Hernández and Kubota, 2016). We showed a novel 
TABLE 3 | Temporal lighting combinations during lettuce propagation and production.

\begin{tabular}{|c|c|}
\hline Day 0-11 (propagation) & Day 11-25 (production) \\
\hline \multirow{6}{*}{$W_{180}$} & $W_{180}$ \\
\hline & $\mathrm{R}_{180}$ \\
\hline & $\mathrm{B}_{20} \mathrm{R}_{160}$ \\
\hline & $\mathrm{B}_{20} \mathrm{G}_{60} \mathrm{R}_{100}$ \\
\hline & $\mathrm{B}_{20} \mathrm{R}_{100} \mathrm{FR}_{60}$ \\
\hline & $\mathrm{B}_{180}$ \\
\hline \multirow[t]{6}{*}{$\mathrm{R}_{180}$} & $W_{180}$ \\
\hline & $\mathrm{R}_{180}$ \\
\hline & $\mathrm{B}_{20} \mathrm{R}_{160}$ \\
\hline & $\mathrm{B}_{20} \mathrm{G}_{60} \mathrm{R}_{100}$ \\
\hline & $\mathrm{B}_{20} \mathrm{R}_{100} \mathrm{FR}_{60}$ \\
\hline & $\mathrm{B}_{180}$ \\
\hline \multirow[t]{6}{*}{$\mathrm{B}_{20} \mathrm{R}_{160}$} & $W_{180}$ \\
\hline & $\mathrm{R}_{180}$ \\
\hline & $\mathrm{B}_{20} \mathrm{R}_{160}$ \\
\hline & $\mathrm{B}_{20} \mathrm{G}_{60} \mathrm{R}_{100}$ \\
\hline & $\mathrm{B}_{20} \mathrm{R}_{100} \mathrm{FR}_{60}$ \\
\hline & $\mathrm{B}_{180}$ \\
\hline \multirow[t]{6}{*}{$\mathrm{B}_{20} \mathrm{G}_{60} \mathrm{R}_{100}$} & $W_{180}$ \\
\hline & $\mathrm{R}_{180}$ \\
\hline & $\mathrm{B}_{20} \mathrm{R}_{160}$ \\
\hline & $\mathrm{B}_{20} \mathrm{G}_{60} \mathrm{R}_{100}$ \\
\hline & $\mathrm{B}_{20} \mathrm{R}_{100} \mathrm{FR}_{60}$ \\
\hline & $\mathrm{B}_{180}$ \\
\hline \multirow[t]{6}{*}{$\mathrm{B}_{20} \mathrm{R}_{100} \mathrm{FR}_{60}$} & $W_{180}$ \\
\hline & $\mathrm{R}_{180}$ \\
\hline & $\mathrm{B}_{20} \mathrm{R}_{160}$ \\
\hline & $\mathrm{B}_{20} \mathrm{G}_{60} \mathrm{R}_{100}$ \\
\hline & $\mathrm{B}_{20} \mathrm{R}_{100} \mathrm{FR}_{60}$ \\
\hline & $\mathrm{B}_{180}$ \\
\hline \multirow[t]{6}{*}{$\mathrm{B}_{180}$} & $W_{180}$ \\
\hline & $\mathrm{R}_{180}$ \\
\hline & $\mathrm{B}_{20} \mathrm{R}_{160}$ \\
\hline & $\mathrm{B}_{20} \mathrm{G}_{60} \mathrm{R}_{100}$ \\
\hline & $\mathrm{B}_{20} \mathrm{R}_{100} \mathrm{FR}_{60}$ \\
\hline & $\mathrm{B}_{180}$ \\
\hline
\end{tabular}

Plants were grown under static or alternate lighting treatments delivered by warmwhite (WW) or mixed blue (B; 400-500 nm), green (G; 500-600 nm), red (R; 600$700 \mathrm{~nm}$ ), and far-red (FR; 700-800 nm) light-emitting diodes (LEDs). The number following each LED type is its respective photon flux density in $\mu \mathrm{mol} \cdot \mathrm{m}^{-2} \cdot \mathrm{s}^{-1}$.

temporal shift of the $\mathrm{B}$ radiation function from growth inhibition during the seedling phase to promotion of leaf expansion, but not shoot weight, during the production phase of lettuce. Therefore, temporal specificity should be considered at least in some crops when evaluating spectral influence on plant growth.

Extension growth in arabidopsis seedlings is regulated by the activities of cryptochromes 1 and 2, which depend on the B photon flux density (Pedmale et al., 2016). Cryptochromes 1 and 2 interacted with phytochrome-interacting factors 4 and 5 in low $\mathrm{B}$ radiation to promote hypocotyl growth, whereas active repression of phytochrome-interacting factor
4 and degradation of cryptochrome 2 and phytochromeinteracting factor 5 in high $\mathrm{B}$ radiation restricted it (Pedmale et al., 2016). In the present study, all leaves of lettuce seedlings grown under high $\mathrm{B}$ radiation exhibited typical inhibition of extension growth. However, as lettuce matured, layers of newer leaves emerged from the central meristem and covered older ones. The newer leaves were directly exposed to abundant $B$ radiation, whereas the older ones became shaded and received less B radiation (Franklin, 2016). Therefore, the responses and interactions of cryptochromes and phytochrome-interacting factors likely differed in upper and lower leaves, which mostly received high and low $B$ radiation, respectively. The decrease in the incident $B$ photon flux density with leaf maturity could explain the shift from inhibited extension growth of seedlings to promoted extension growth of mature plants under externally static and strong $B$ radiation.

We also observed dynamic growth responses of lettuce to substitutional $G$ radiation. Substituting $60 \mu \mathrm{mol} \cdot \mathrm{m}^{-2} \cdot \mathrm{s}^{-1}$ of $\mathrm{G}$ radiation for $\mathrm{R}$ radiation influenced lettuce shoot weight and leaf length differently on days 11 and 25. It did not affect shoot fresh and dry weights but increased leaf length on day 11. In contrast, it decreased shoot fresh and dry weights but did not affect leaf length on day 25. However, when growing lettuce "Rouxai" under WW radiation for 4 days before varying spectral treatments, plants under $B_{20} G_{60} R_{100}$ had higher shoot fresh weight, but similar shoot dry weight and leaf length, compared to those under $\mathrm{B}_{20} \mathrm{R}_{160}$ on day 30 or 33 (Meng et al., 2020). In a similar study, substituting $36 \mu \mathrm{mol} \cdot \mathrm{m}^{-2} \cdot \mathrm{s}^{-1}$ of $\mathrm{G}$ radiation for $\mathrm{R}$ radiation in static $\mathrm{B}_{24} \mathrm{R}_{126}$ increased shoot fresh and dry weights and leaf area of lettuce "Waldmann's Green" on day 28, whereas G radiation alone from fluorescent lamps decreased them (Kim et al., 2004). These discrepancies can at least partly be attributed to adaptive responses to $G$ radiation in photosynthetic acclimation and plant architecture, which could change throughout growth phases based on spectral history, sampling time, and other environmental factors.

We consider two phenomena to explain the shifting responses to $\mathrm{G}$ radiation in this study. First, the commonly cited McCree curve shows the spectral region near $G$ radiation had the lowest quantum yield when data were expressed on an absorbed photon basis considering the leaf absorption spectrum (McCree, 1972). However, when the same data were expressed on an incident photon basis without considering the leaf absorption spectrum, the photosynthetic efficacy of incident $G$ radiation was comparable to that of incident $\mathrm{B}$ radiation and about half that of incident $\mathrm{R}$ radiation (McCree, 1972). Therefore, partial substitution of incident $R$ radiation with incident $G$ radiation could reduce overall photosynthetic efficacy and thus weight gain in some species and cultivars. Indeed, at the same B photon flux density of 15,30 , or $45 \mu \mathrm{mol} \cdot \mathrm{m}^{-2} \cdot \mathrm{s}^{-1}$, substituting $15 \mu \mathrm{mol} \cdot \mathrm{m}^{-2} \cdot \mathrm{s}^{-1}$ of $\mathrm{G}$ radiation for $\mathrm{R}$ radiation at a constant PPFD of $150 \mu \mathrm{mol} \cdot \mathrm{m}^{-2} \cdot \mathrm{s}^{-1}$ reduced the leaf net photosynthetic rate of lettuce "Green Skirt" without affecting leaf morphology (Kang et al., 2016). In addition, the leaf net photosynthetic rate of lettuce was lower under $\mathrm{G}$ radiation alone than under $\mathrm{R}$ or $\mathrm{B}$ 

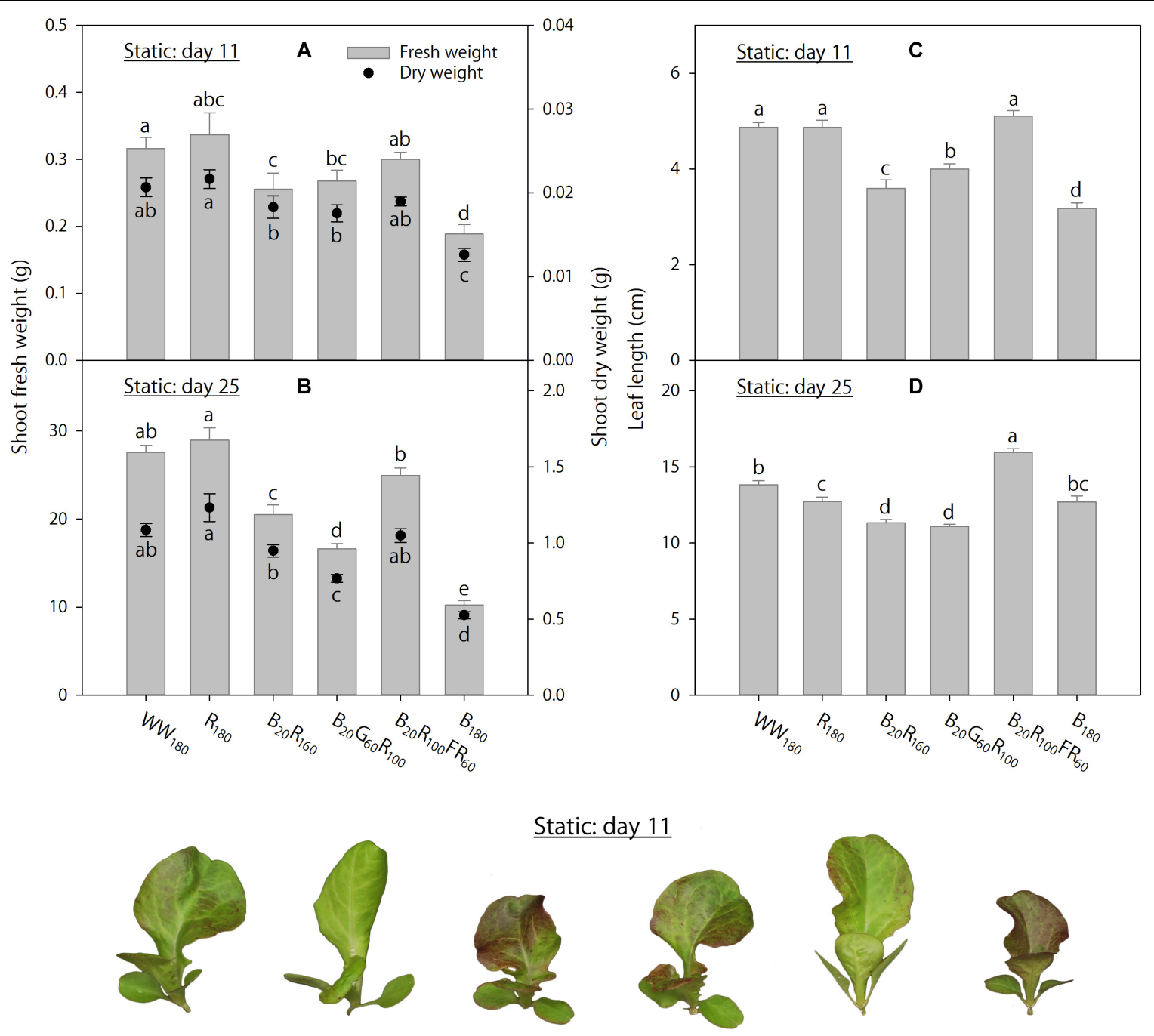

\section{Static: day 25}
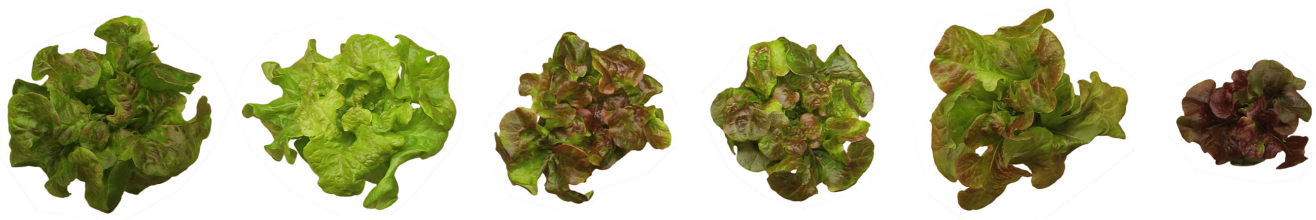

$\mathrm{WW}_{180}$

$\mathrm{R}_{180}$

$\mathrm{B}_{20} \mathrm{R}_{160}$

$B_{20} G_{60} R_{100}$

$\mathrm{B}_{20} \mathrm{R}_{100} \mathrm{FR}_{60}$

$\mathrm{B}_{180}$

FIGURE 2 | Shoot fresh and dry weights and leaf length on days 11 and 25 of lettuce "Rouxai" grown under six static lighting treatments delivered by warm-white (WW) or mixed blue (B; 400-500 nm), green (G; 500-600 nm), red (R; 600-700 nm), and far-red (FR; 700-800 nm) light-emitting diodes (LEDs). The number for each LED type is its photon flux density in $\mu \mathrm{mol} \cdot \mathrm{m}^{-2} \cdot \mathrm{s}^{-1}$. Means followed by different letters within each parameter are significantly different based on Tukey's honestly significant difference test $(\alpha=0.05)$. Error bars show standard errors.

radiation alone, $\mathrm{B}+\mathrm{R}$ radiation, or $\mathrm{B}+\mathrm{G}+\mathrm{R}$ radiation (Kim et al., 2004; Kang et al., 2016).

Second, when delivered at a sufficiently high photon flux density, $G$ radiation can reverse B-induced growth inhibition and elicit the shade-avoidance response, such as accelerated hypocotyl and petiole elongation (Folta and Maruhnich, 2007;
Zhang et al., 2011; Wang and Folta, 2013). In arabidopsis, G radiation reversed activation of cryptochrome 1 and degradation of cryptochrome 2 by B radiation (Bouly et al., 2007). Accumulation of cryptochrome 2 in substitutional G radiation can promote activity of phytochrome-interacting factors 4 and 5 and thus increase extension growth (Pedmale et al., 2016). 

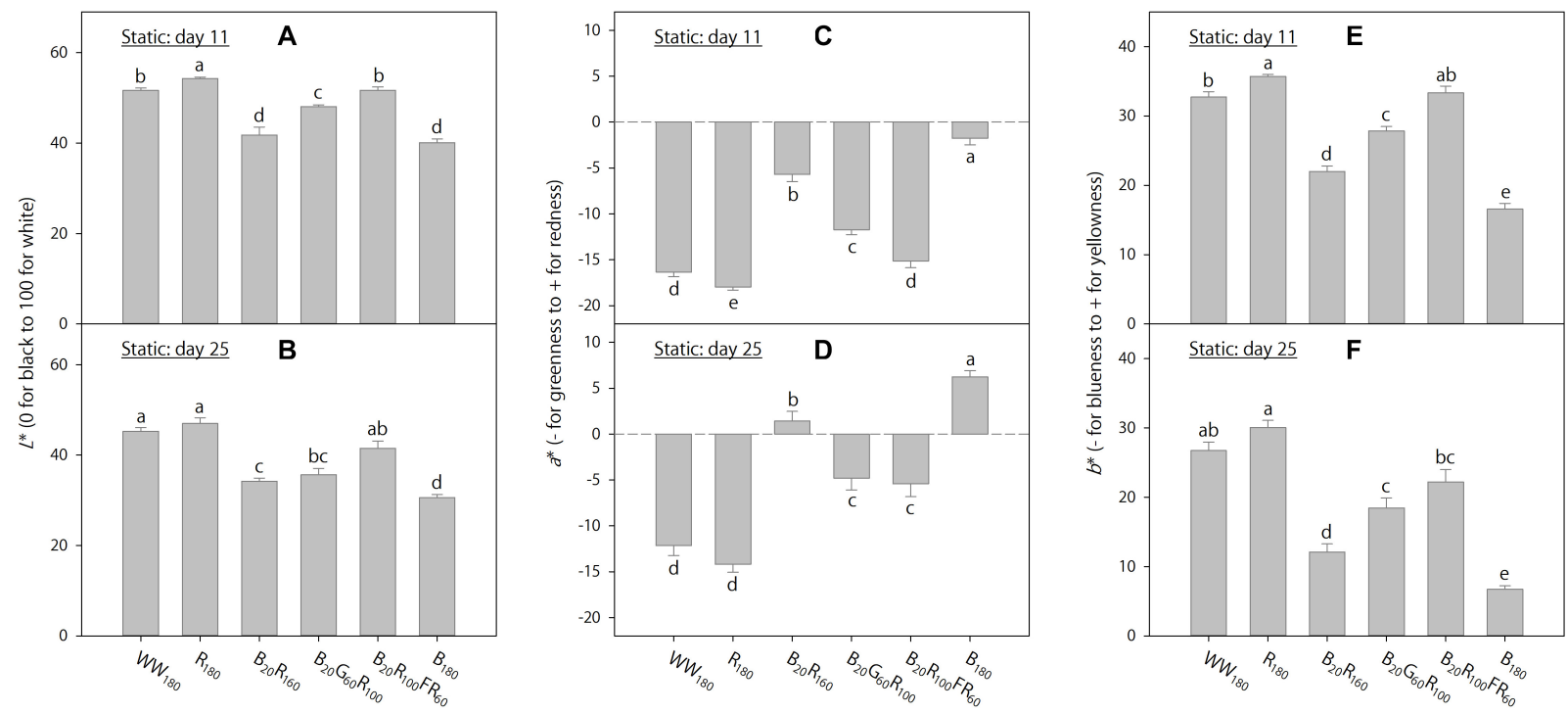

FIGURE 3 | Lab color space parameters on days 11 and 25 of lettuce "Rouxai" grown under six static lighting treatments delivered by warm-white (WW) or mixed blue (B; 400-500 nm), green (G; 500-600 nm), red (R; 600-700 nm), and far-red (FR; 700-800 nm) light-emitting diodes (LEDs). The number for each LED type is its photon flux density in $\mu \mathrm{mol} \cdot \mathrm{m}^{-2} \cdot \mathrm{s}^{-1}$. Means followed by different letters in each graph are significantly different based on Tukey's honestly significant difference test $(\alpha=0.05)$. Error bars show standard errors.

Besides stem growth, partially substituting $\mathrm{G}$ radiation for $\mathrm{R}$ radiation in constant $\mathrm{B}$ radiation promoted leaf expansion of lettuce "Waldmann's Green" (Kim et al., 2004), which likely increased light capture for photosynthesis. In addition, completely substituting $G$ radiation for $R$ radiation in $B_{80} R_{80}$ increased leaf area of tomato (S. lycopersicum L.) seedlings but did not influence shoot fresh or dry weight (Wollaeger and Runkle, 2014), which resembles the lettuce seedling response to $\mathrm{G}$ radiation on day 11 in the present study. In other studies, the inclusion of $\mathrm{G}$ radiation generally did not influence plant growth (Hernández and Kubota, 2016; Snowden et al., 2016), indicating $G$ radiation effects could depend on the genotype, spectral context, and timing of treatments.

Taken together, the varying responses to substitutional $G$ radiation observed on days 11 and 25 in the present study could be attributed to a changing balance between its reduction of instantaneous photosynthesis and its enhancement of wholeplant photosynthesis through increased leaf expansion and light interception. As lettuce grown under $\mathrm{B}+\mathrm{R}$ radiation received less overall $\mathrm{B}$ radiation later in production because of leaf layering, its sensitivity to additional shade signals such as $G$ radiation (when added) subsided. This could explain why leaf length under $B_{20} G_{60} R_{100}$ was initially greater than that under $\mathrm{B}_{20} \mathrm{R}_{160}$ on day 11 but eventually was similar to it on day 25 . Increased leaf expansion likely compensated for reduced net photosynthesis in $\mathrm{G}$ radiation on day 11 , leading to comparable shoot weight under $B_{20} R_{160}$ and $B_{20} G_{60} R_{100}$. The lack of such compensation on day 25 resulted in lower shoot weight under substitutional $\mathrm{G}$ radiation.

In contrast, FR radiation was a stronger shade signal than $G$ radiation at the same photon flux density (Meng et al., 2019) and consistently increased leaf length by $41-42 \%$ on days 11 and 25 when added to $\mathrm{B}+\mathrm{R}$ radiation. Lettuce grown under $\mathrm{B}_{20} \mathrm{R}_{100} \mathrm{FR}_{60}$ had similar shoot dry weight and $17-22 \%$ higher shoot fresh weight (partly due to increases in moisture content) compared to that under $\mathrm{B}_{20} \mathrm{R}_{160}$, although $\mathrm{B}_{20} \mathrm{R}_{100} \mathrm{FR}_{60}$ was $32 \%$ lower in the PPFD and 26\% lower in the YPFD. The similar TPFDs across all lighting treatments cannot explain differences in shoot dry weight. In addition, Figure 7 plots shoot dry weight against the relative PPFD, YPFD, leaf length, PPFD $\times$ leaf length, or YPFD $\times$ leaf length for all lighting treatments. Only YPFD $\times$ leaf length was linearly related with shoot dry weight (Figure 7). Therefore, the similar dry weight with the FR radiation substitution $\left(B_{20} R_{100} F_{60}\right.$ versus $\left.B_{20} R_{160}\right)$ was likely the product of the reduced YPFD (74\% of that for $\mathrm{B}_{20} \mathrm{R}_{160}$ ) and increased light interception (141-142\% of that under $\mathrm{B}_{20} \mathrm{R}_{160}$ ). This suggests that changes in shoot dry weight can be predicted by multiplying percentage changes in the YPFD (to account for the changing instantaneous photosynthetic rate and quantum efficiency) and percentage changes in leaf size (to account for changing light interception due to morphological acclimation). The YPFD is a better predictor of plant biomass than the PPFD because it accounts for relative quantum efficiency and the contribution of FR radiation to net photosynthesis, albeit less significant than $\mathrm{B}, \mathrm{G}$, or $\mathrm{R}$ radiation. Lastly, light interception may be better estimated with leaf area instead of leaf length.

Increasing B:R intensified red coloration of lettuce "Rouxai," whereas substitutional G or FR radiation decreased B-induced anthocyanin accumulation of plants treated with static lighting on days 11 and 25. Similarly, increasing the B photon flux density from 20 to $80 \mu \mathrm{mol} \cdot \mathrm{m}^{-2} \cdot \mathrm{s}^{-1}$ increased anthocyanin concentration of lettuce "Red Sails" in a dose-dependent manner; however, the inclusion of $G$ radiation reduced anthocyanin accumulation in lettuce "Red Sails" and arabidopsis 


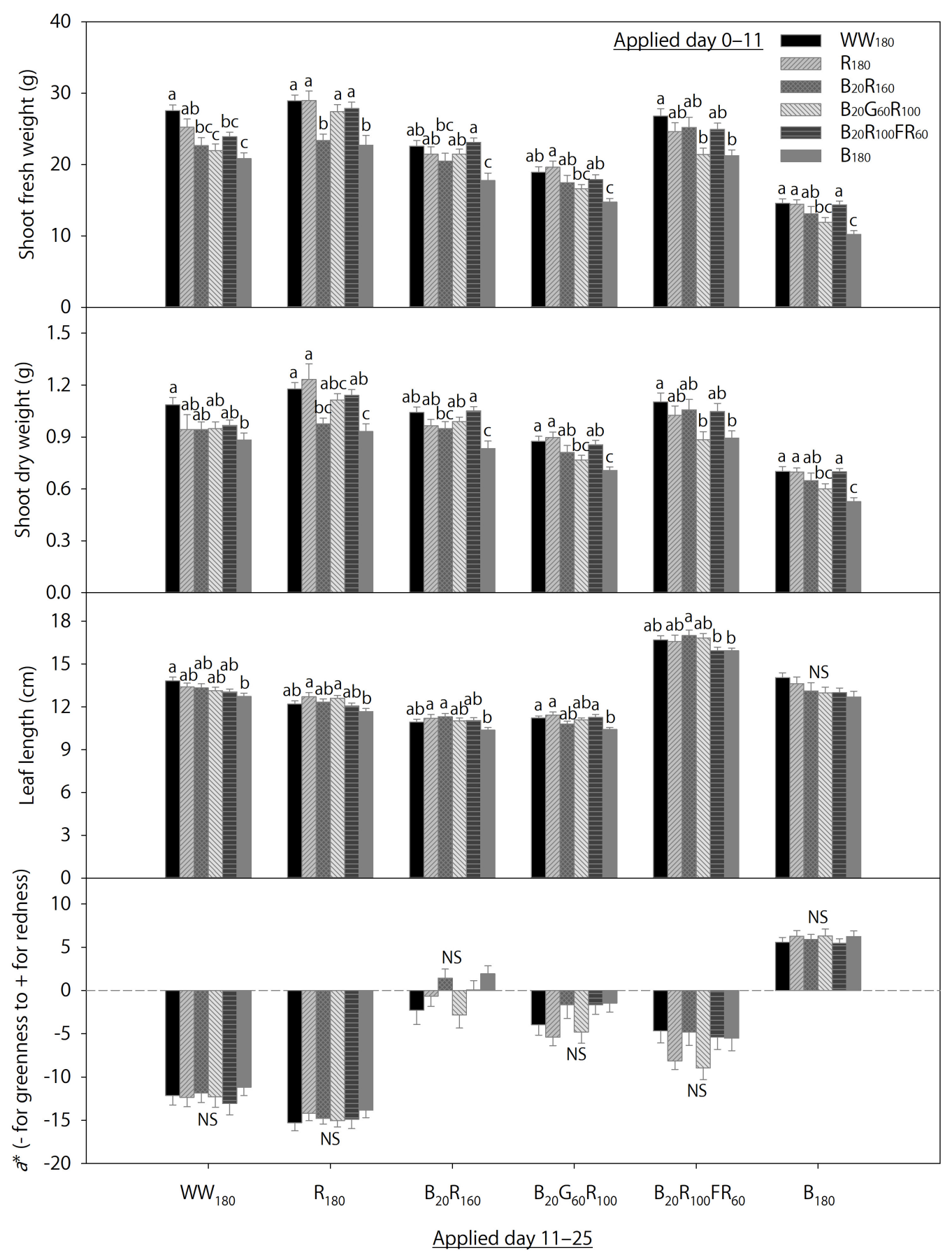

FIGURE 4 | Shoot fresh and dry weights, leaf length, and the a* color space coordinate of lettuce "Rouxai" on day 25. Plants were grown under each of six lighting treatments delivered by warm-white (WW) or mixed blue (B; 400-500 nm), green (G; 500-600 nm), red (R; 600-700 nm), and far-red (FR; 700-800 nm) light-emitting diodes (LEDs) during day $0-11$, transferred to all six treatments on day 11, and grown until day 25 . The number for each LED type is its photon flux density in $\mu \mathrm{mol} \cdot \mathrm{m}^{-2} \cdot \mathrm{s}^{-1}$. Means followed by different letters within each parameter and treatment applied during day 11-25 are significantly different based on Tukey's honestly significant difference test $(\alpha=0.05)$. NS, non-significant. Error bars show standard errors.

(Zhang and Folta, 2012). Upregulation of anthocyanin accumulation by $\mathrm{B}$ radiation is mediated by cryptochrome 1 and reversed by $\mathrm{G}$ radiation (Bouly et al., 2007). Although FR radiation increases anthocyanin accumulation during de-etiolation of arabidopsis seedlings through phytochrome A, which stabilizes Long Hypocotyl 5 (HY5) to promote expression of anthocyanin biosynthetic genes ( $\mathrm{Li}$ et al., 2014; Liu et al., 2015), it can also decrease anthocyanin accumulation through phytochrome 

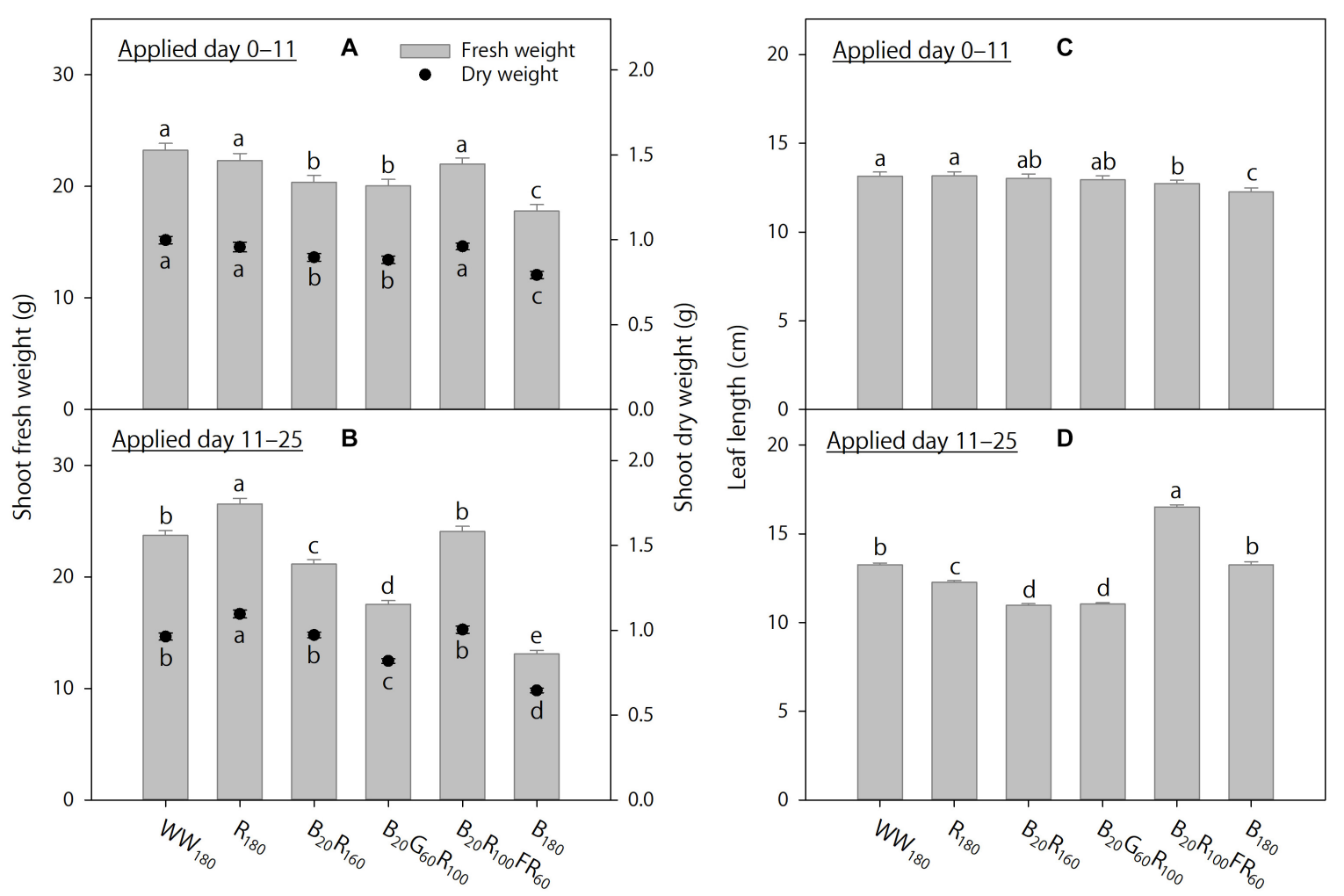

FIGURE 5 | The effects of initial (applied day 0-11) and eventual (applied day 11-25) lighting treatments on pooled final shoot fresh and dry weights and leaf length of lettuce "Rouxai" on day 25. Plants were grown under each of six lighting treatments delivered by warm-white (WW) or mixed blue (B; $400-500$ nm), green (G; 500-600 nm), red (R; 600-700 nm), and far-red (FR; 700-800 nm) light-emitting diodes (LEDs) during day 0-11, transferred to all six treatments on day 11, and grown until day 25. The number for LED type is its photon flux density in $\mu \mathrm{mol} \cdot \mathrm{m}^{-2} \cdot \mathrm{s}^{-1}$. Means followed by different letters within each parameter and graph are significantly different based on Tukey's honestly significant difference test $(\alpha=0.05)$. Error bars show standard errors.

B (Zheng et al., 2013). In addition, partial substitution of white radiation with $\mathrm{FR}$ radiation decreased anthocyanin concentration of lettuce "Red Cross" (Li and Kubota, 2009). Therefore, G and FR radiation likely antagonize $\mathrm{B}$ radiation in regulation of anthocyanin accumulation of red-leaf lettuce through cryptochromes and phytochromes, respectively. Alternatively, with similar total anthocyanin content per leaf, anthocyanin concentration can decrease as leaf area increases with G or FR radiation. Direct biosynthetic regulation and the "dilution" effect could occur concurrently and warrant further investigation.

When lettuce "Rouxai" was grown under different initial treatments day $0-11$ but the same eventual treatments day 1125 , initial light quality had a residual effect on final shoot fresh and dry weights, responses of which generally resembled those under static treatments. For example, for plants transferred to the same $R_{180}$ or $B_{180}$ treatment on day 11 , final shoot dry weight was greater when initially grown under $R_{180}$ than under $B_{180}$. In a similar study, when lettuce "Grand Rapids" was transferred from $R_{100}$ to $B_{100}$ or from $B_{100}$ to $R_{100}$ on day 7 , shoot dry weight of mature lettuce was primarily influenced by light quality applied before, rather than after, the transfer (Eskins et al., 1995). Contrary to typical B-induced growth inhibition, shoot dry weight and leaf area were consistently greater under $\mathrm{B}_{100}$ than under $\mathrm{R}_{100}$ applied during seedling development or throughout the experiment (Eskins et al., 1995). Such unique B radiation responses may be species- and cultivar-specific. In addition, a temporal shift of B radiation responses was previously reported in lettuce "Banchu Red Fire," which was grown under fluorescent lamps day $0-10 ; \mathrm{R}_{100}, \mathrm{~B}_{50} \mathrm{R}_{50}$, or $\mathrm{B}_{100}$ day $10-17$; and then sunlight with supplemental fluorescent lamps day 17-45 (Johkan et al., 2010). Increasing B:R during the seedling phase decreased leaf area and fresh weight on day 17 but increased them on day 45 (Johkan et al., 2010). Although spectral effects varied in these and our studies, they all showed lasting influences of light quality applied during the seedling phase on subsequent plant growth. A sustained environmental treatment delivered early in seedling development could persist into the mature phase possibly by DNA methylation or irreversible activation or suppression of growth-related genes (Bird, 1993; Eskins et al., 1995). The latency of early light signals was also evident in accelerated flowering of mature snapdragon and petunia (Petunia $\times$ hybrida L.) by additional FR radiation applied during the seedling phase (Park and Runkle, 2017, 2018).

Although light quality during the seedling phase modified shoot fresh and dry weights of mature lettuce, the magnitude of this modification was less pronounced than that by light quality in the mature phase. As the plant underwent the exponential growing phase, light interception increased drastically 

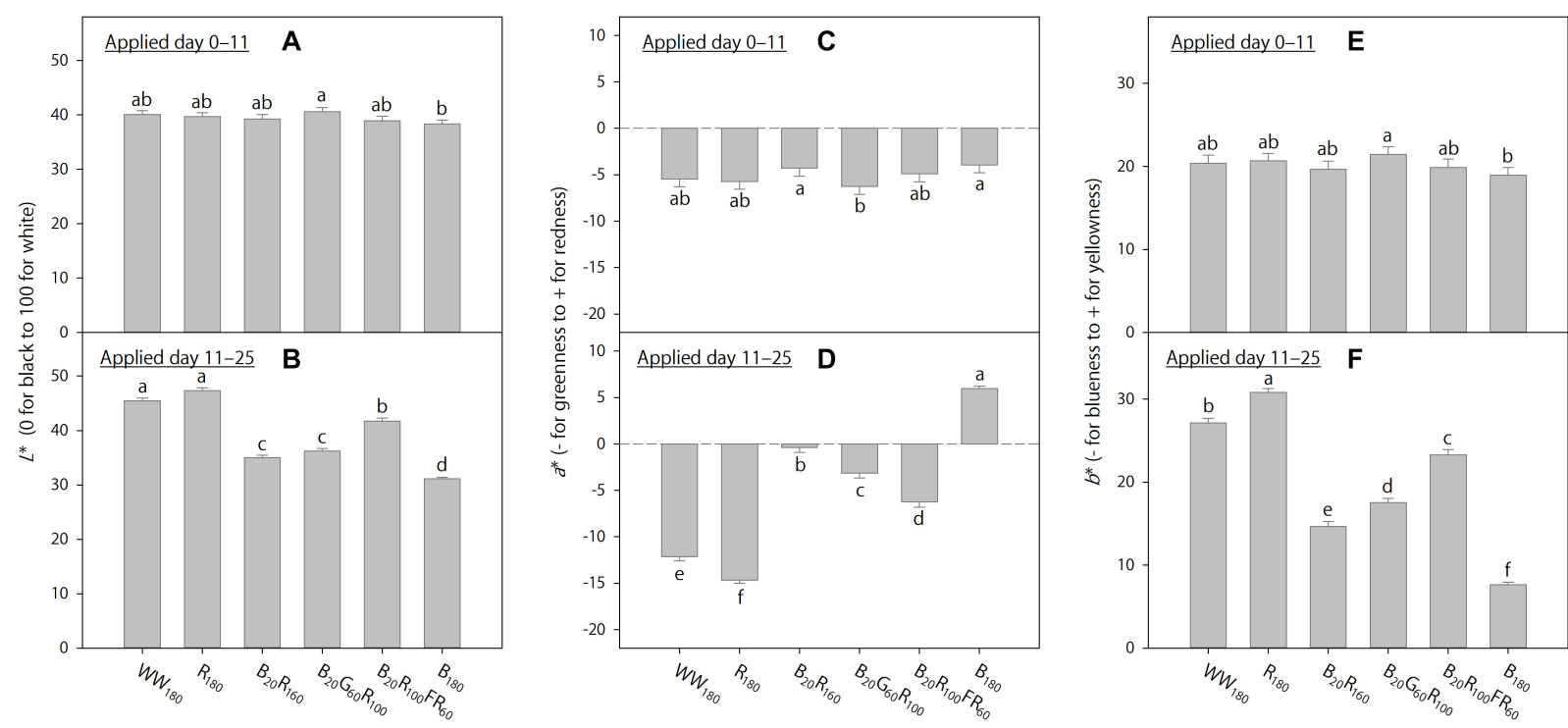

FIGURE 6 | The effects of initial (applied day 0-11) and eventual (applied day 11-25) lighting treatments on pooled final Lab color space parameters of lettuce "Rouxai" on day 25. Plants were grown under each of six lighting treatments delivered by warm-white (WW) or mixed blue (B; 400-500 nm), green (G; 500-600 nm), red (R; 600-700 nm), and far-red (FR; 700-800 nm) light-emitting diodes (LEDs) during day 0-11, transferred to all six treatments on day 11, and grown until day 25 . The number for each LED type is its photon flux density in $\mu \mathrm{mol} \cdot \mathrm{m}^{-2} \cdot \mathrm{s}^{-1}$. Means followed by different letters within each graph are significantly different based on Tukey's honestly significant difference test $(\alpha=0.05)$. Error bars show standard errors.
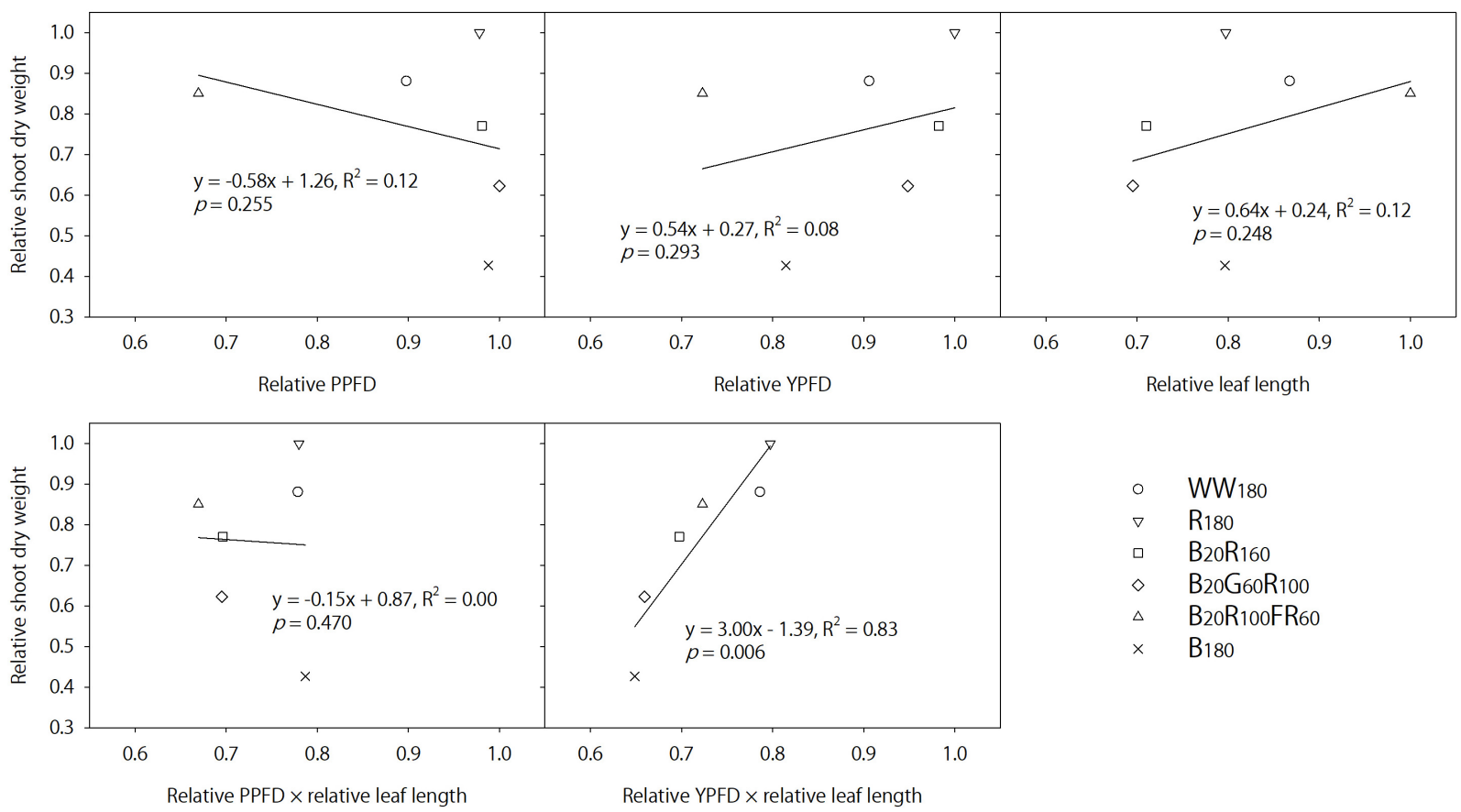

FIGURE 7 | Relative shoot dry weight of lettuce "Rouxai" on day 25 plotted against the relative photosynthetic photon flux density (PPFD), relative yield photon flux density (YPFD), relative leaf length, relative PPFD $\times$ relative leaf length, and relative YPFD $\times$ relative leaf length. Plants were grown under six static lighting treatments delivered by warm-white (WW) or mixed blue (B; 400-500 nm), green (G; 500-600 nm), red (R; 600-700 nm), and far-red (FR; 700-800 nm) light-emitting diodes (LEDs). The number for each LED type is its photon flux density in $\mu \mathrm{mol} \cdot \mathrm{m}^{-2} \cdot \mathrm{s}^{-1}$. Data were averaged for each lighting treatment from two blocks. Linear regression equations, coefficients of determination, and p-values for slopes are provided. The only significant linear relationship occurs between relative YPFD $\times$ relative leaf length and relative shoot dry weight $(\alpha=0.05)$. 
with leaf development, which likely led to greater impacts of eventual treatments on photosynthesis and morphology. In addition, leaf length and coloration of mature lettuce were primarily controlled by eventual lighting treatments and negligibly affected by initial ones. The greater influence of eventual light quality on foliage coloration could at least partly be attributed to rapid anthocyanin accumulation in lettuce under light stresses within days (Owen and Lopez, 2015). In general, final lettuce shoot weight, leaf length, and coloration were similar under lighting treatments applied day 0-25 and day 1125 , further highlighting the predominant role of eventual light quality. Nonetheless, the lasting initial spectral effects exerted significant influence on final shoot weight and thus should be considered for growth of both seedlings and mature plants. In another treatment-switching experiment, spectral effects during the seedling (day 0-14) and mature (day 14-28) phases on final growth of lettuce "Crispa" depended on specific lighting combinations (Chang and Chang, 2014). Therefore, dynamic lighting strategies should be based on specific cultivars and potentially interactive environmental factors such as light quality, the PPFD, and temperature.

The following conclusions are in response to the three original hypotheses. First, effects of light quality applied during the seedling phase persisted into the mature phase, although they were less pronounced than those applied during the mature phase. Second, substituting substantial G radiation for $\mathrm{R}$ radiation did not influence growth of seedlings but decreased growth of mature lettuce. Third, B radiation alone decreased lettuce shoot weight during both the seedling and mature phases. However, compared to $\mathrm{R}$ radiation, $\mathrm{B}$ radiation alone suppressed leaf elongation during the seedling phase but promoted it during the mature phase. In addition to testing hypotheses, we conclude temporally alternating light quality improved precision of phenotype control over static lighting. Thus, differential lighting treatments could be delivered at various developmental stages to optimize crop growth and quality attributes. Our results suggest that lettuce biomass can be maximized with WW, R,

\section{REFERENCES}

Armbruster, U., Carrillo, L. R., Venema, K., Pavlovic, L., Schmidtmann, E., Kornfeld, A., et al. (2014). Ion antiport accelerates photosynthetic acclimation in fluctuating light environments. Nat. Commun. 5:5439. doi: 10.1038/ ncomms6439

Bird, A. P. (1993). Imprints on islands. Curr. Biol. 3, 275-277. doi: 10.1016/09609822(93)90177-P

Bouly, J. P., Schleicher, E., Dionisio-Sese, M., Vandenbussche, F., Van Der Straeten, D., Bakrim, N., et al. (2007). Cryptochrome blue light photoreceptors are activated through interconversion of flavin redox states. J. Biol. Chem. 282, 9383-9391. doi: 10.1074/jbc.M609842200

Brodersen, C. R., and Vogelmann, T. C. (2010). Do changes in light direction affect absorption profiles in leaves? Funct. Plant Biol. 37, 403-412. doi: 10.1071/ FP09262

Carvalho, S. D., and Folta, K. M. (2014a). Environmentally modified organismsexpanding genetic potential with light. Critical Rev. Plant Sci. 33, 486-508. doi: 10.1080/07352689.2014.929929

Carvalho, S. D., and Folta, K. M. (2014b). Sequential light programs shape kale (Brassica napus) sprout appearance and alter metabolic and nutrient content. Hortic. Res. 1:8. doi: 10.1038/hortres.2014.8 or $\mathrm{B}+\mathrm{R}+\mathrm{FR}$ radiation during propagation, followed by $\mathrm{R}$ radiation during production. End-of-production $\mathrm{B}$ radiation can be used to induce anthocyanin accumulation.

\section{DATA AVAILABILITY STATEMENT}

The raw data supporting the conclusions of this article will be made available by the authors, without undue reservation.

\section{AUTHOR CONTRIBUTIONS}

QM conceived and performed the experiment, collected and analyzed data, and wrote the first draft of the manuscript. ER was the recipient of funds and reviewed experimental design. Both authors contributed to the manuscript revision and approved the final version.

\section{FUNDING}

This work was supported by Michigan State University AgBioResearch Project GREEEN GR17-072 and the USDA National Institute of Food and Agriculture, Hatch project 192266.

\section{ACKNOWLEDGMENTS}

The authors thank Cary Mitchell, Jennifer Boldt, and Roberto Lopez for manuscript reviews and suggestions; David Hamby, Rodrigo Pereyra, Charles Brunault, Alan Sarkisian, and Dorian Spero from OSRAM Innovation for lighting support; Nathan Kelly for experimental assistance; Steve Brooks for technical assistance; Randy Beaudry, Dan Brainard, and Roberto Lopez for instruments; and material donations from Grodan and JR Peters, Inc.

Cerdán, P. D., and Chory, J. (2003). Regulation of flowering time by light quality. Nature 423, 881-885. doi: 10.1038/nature01636

Chang, C. L., and Chang, K. P. (2014). The growth response of leaf lettuce at different stages to multiple wavelength-band light-emitting diode lighting. Sci. Hortic. 179, 78-84. doi: 10.1016/j.scienta.2014.09.013

Chen, X. L., Guo, W. Z., Xue, X. Z., Wang, L. C., and Qiao, X. J. (2014). Growth and quality responses of 'Green Oak Leaf' lettuce as affected by monochromic or mixed radiation provided by fluorescent lamp (FL) and light-emitting diode (LED). Sci. Hortic. 172, 168-175. doi: 10.1016/j.scienta.2014.04.009

Cope, K. R., Snowden, M. C., and Bugbee, B. (2014). Photobiological interactions of blue light and photosynthetic photon flux: effects of monochromatic and broadspectrum light sources. Photochem. Photobiol. 90, 574-584. doi: 10.1111/php. 12233

Demmig-Adams, B., Cohu, C. M., Muller, O., and Adams, W. W. (2012). Modulation of photosynthetic energy conversion efficiency in nature: from seconds to seasons. Photosynth. Res. 113, 75-88. doi: 10.1007/s11120-0129761-6

Eskins, K., Warner, K., and Felker, F. C. (1995). Light quality during early seedling development influences the morphology and bitter taste intensity of mature lettuce (Lactuca sativa) leaves. J. Plant Physiol. 147, 709-713. doi: 10.1016/ S0176-1617(11)81482-3 
Folta, K. M., and Maruhnich, S. A. (2007). Green light: a signal to slow down or stop. J. Exp. Bot. 58, 3099-3111. doi: 10.1093/jxb/erm130

Franklin, K. A. (2016). Photomorphogenesis: plants feel blue in the shade. Curr. Biol. 26, R1275-R1276. doi: 10.1016/j.cub.2016.10.039

Gómez, C., and Jiménez, J. (2020). Effect of end-of-production high-energy radiation on nutritional quality of indoor-grown red-leaf lettuce. HortScience 55:7. doi: 10.21273/HORTSCI15030-20

Hernández, R., and Kubota, C. (2016). Physiological responses of cucumber seedlings under different blue and red photon flux ratios using LEDs. Environ. Exp. Bot. 121, 66-74. doi: 10.1016/j.envexpbot.2015.04.001

Jishi, T., Kimura, K., Matsuda, R., and Fujiwara, K. (2016). Effects of temporally shifted irradiation of blue and red LED light on cos lettuce growth and morphology. Sci. Hortic. 198, 227-232. doi: 10.1016/j.scienta.2015.12.005

Johkan, M., Shoji, K., Goto, F., Hashida, S. N., and Yoshihara, T. (2010). Blue light-emitting diode light irradiation of seedlings improves seedling quality and growth after transplanting in red leaf lettuce. HortScience 45, 1809-1814. doi: 10.21273/HORTSCI.45.12.1809

Kang, W. H., Park, J. S., Park, K. S., and Son, J. E. (2016). Leaf photosynthetic rate, growth, and morphology of lettuce under different fractions of red, blue, and green light from light-emitting diodes (LEDs). Hortic. Environ. Biotechnol. 57, 573-579. doi: 10.1007/s13580-016-0093-x

Kim, H. H., Goins, G. D., Wheeler, R. M., and Sager, J. C. (2004). Greenlight supplementation for enhanced lettuce growth under red-and blue-lightemitting diodes. HortScience 39, 1617-1622. doi: 10.21273/HORTSCI.39.7. 1617

Kopsell, D. A., Sams, C. E., and Morrow, R. C. (2015). Blue wavelengths from LED lighting increase nutritionally important metabolites in specialty crops. HortScience 50, 1285-1288. doi: 10.21273/HORTSCI.50.9.1285

Lee, J. S., Lim, T. G., and Kim, Y. H. (2014). Growth and phytochemicals in lettuce as affected by different ratios of blue to red LED radiation. Acta Hortic. 1037, 843-848. doi: 10.17660/ActaHortic.2014.1037.112

Li, Q., and Kubota, C. (2009). Effects of supplemental light quality on growth and phytochemicals of baby leaf lettuce. Environ. Exp. Bot. 67, 59-64. doi: 10.1016/j.envexpbot.2009.06.011

Li, T., Jia, K. P., Lian, H. L., Yang, X., Li, L., and Yang, H. Q. (2014). Jasmonic acid enhancement of anthocyanin accumulation is dependent on phytochrome A signaling pathway under far-red light in Arabidopsis. Biochem. Biophys. Res. Commun. 454, 78-83. doi: 10.1016/j.bbrc.2014.10.059

Liu, X. Y., Chang, T. T., Guo, S. R., Xu, Z. G., and Li, J. (2009). Effect of different light quality of LED on growth and photosynthetic character in cherry tomato seedling. Acta. Hortic. 907, 325-330. doi: 10.17660/ActaHortic.2011.907.53

Liu, Z., Zhang, Y., Wang, J., Li, P., Zhao, C., Chen, Y., et al. (2015). Phytochromeinteracting factors PIF4 and PIF5 negatively regulate anthocyanin biosynthesis under red light in Arabidopsis seedlings. Plant Sci. 238, 64-72. doi: 10.1016/j. plantsci.2015.06.001

McCree, K. J. (1972). The action spectrum, absorptance and quantum yield of photosynthesis in crop plants. Agric. Meteorol. 9, 191-216. doi: 10.1016/00021571(71)90022-7

Meng, Q., Boldt, J., and Runkle, E. S. (2020). Blue radiation interacts with green radiation to influence growth and predominantly controls quality attributes of lettuce. J. Am. Soc. Hortic. Sci. 145, 75-87. doi: 10.21273/JASHS04759-19

Meng, Q., Kelly, N., and Runkle, E. S. (2019). Substituting green or far-red radiation for blue radiation induces shade avoidance and promotes growth in lettuce and kale. Environ. Exp. Bot. 162, 383-391. doi: 10.1016/j.envexpbot.2019.03.016

Meng, Q., and Runkle, E. S. (2019). Far-red radiation interacts with relative and absolute blue and red photon flux densities to regulate growth, morphology, and pigmentation of lettuce and basil seedlings. Sci. Hortic. 255, 269-280. doi: 10.1016/j.scienta.2019.05.030

Ohashi-Kaneko, K., Takase, M., Kon, N., Fujiwara, K., and Kurata, K. (2007). Effect of light quality on growth and vegetable quality in leaf lettuce, spinach and komatsuna. Environ. Control Biol. 45, 189-198. doi: 10.2525/ecb.45.189
Owen, W. G., and Lopez, R. G. (2015). End-of-production supplemental lighting with red and blue light-emitting diodes (LEDs) influences red pigmentation of four lettuce varieties. HortScience 50, 676-684. doi: 10.21273/HORTSCI.50. 5.676

Park, Y., and Runkle, E. S. (2017). Far-red radiation promotes growth of seedlings by increasing leaf expansion and whole-plant net assimilation. Environ. Exp. Bot. 136, 41-49. doi: 10.1016/j.envexpbot.2016.12.013

Park, Y., and Runkle, E. S. (2018). Far-red radiation and photosynthetic photon flux density independently regulate seedling growth but interactively regulate flowering. Environ. Exp. Bot. 155, 206-216. doi: 10.1016/j.envexpbot.2018. 06.033

Pedmale, U. V., Huang, S. S. C., Zander, M., Cole, B. J., Hetzel, J., Ljung, K., et al. (2016). Cryptochromes interact directly with PIFs to control plant growth in limiting blue light. Cell 164, 233-245. doi: 10.1016/j.cell.2015. 12.018

Sager, J. C., Smith, W. O., Edwards, J. L., and Cyr, K. L. (1988). Photosynthetic efficiency and phytochrome photoequilibria determination using spectral data. Trans. Am. Soc. Agric. Eng. 31, 1882-1889. doi: 10.13031/2013. 30952

Snowden, M. C., Cope, K. R., and Bugbee, B. (2016). Sensitivity of seven diverse species to blue and green light: interactions with photon flux. PLoS One 11:e0163121. doi: 10.1371/journal.pone.0163121

Son, K. H., Lee, J. H., Oh, Y., Kim, D., Oh, M. M., and In, B. C. (2017). Growth and bioactive compound synthesis in cultivated lettuce subject to light-quality changes. HortScience 52, 584-591. doi: 10.21273/HORTSCI11592-16

Son, K. H., and Oh, M. M. (2013). Leaf shape, growth, and antioxidant phenolic compounds of two lettuce cultivars grown under various combinations of blue and red light-emitting diodes. HortScience 48, 988-995. doi: 10.21273/ HORTSCI.48.8.988

Terashima, I., Fujita, T., Inoue, T., Chow, W. S., and Oguchi, R. (2009). Green light drives leaf photosynthesis more efficiently than red light in strong white light: revisiting the enigmatic question of why leaves are green. Plant Cell Physiol. 50, 684-697. doi: 10.1093/pcp/pcp034

Wang, Y., and Folta, K. M. (2013). Contributions of green light to plant growth and development. Am. J. Bot. 100, 70-78. doi: 10.3732/ajb.1200354

Wollaeger, H. M., and Runkle, E. S. (2014). Growth of impatiens, petunia, salvia, and tomato seedlings under blue, green, and red light-emitting diodes. HortScience 49, 734-740. doi: 10.21273/HORTSCI.49.6.734

Wollaeger, H. M., and Runkle, E. S. (2015). Growth and acclimation of impatiens, salvia, petunia, and tomato seedlings to blue and red light. HortScience 50, 522-529. doi: 10.21273/HORTSCI.50.4.522

Zhang, T., and Folta, K. M. (2012). Green light signaling and adaptive response. Plant Signal. Behav. 7, 75-78. doi: 10.4161/psb.7.1.18635

Zhang, T., Maruhnich, S. A., and Folta, K. M. (2011). Green light induces shade avoidance symptoms. Plant Physiol. 157, 1528-1536. doi: 10.1104/pp.111. 180661

Zheng, X., Wu, S., Zhai, H., Zhou, P., Song, M., Su, L., et al. (2013). Arabidopsis phytochrome B promotes SPA1 nuclear accumulation to repress photomorphogenesis under far-red light. Plant Cell 25, 115-133. doi: 10.1105/ tpc.112.107086

Conflict of Interest: The authors declare that the research was conducted in the absence of any commercial or financial relationships that could be construed as a potential conflict of interest.

Copyright (c) 2020 Meng and Runkle. This is an open-access article distributed under the terms of the Creative Commons Attribution License (CC BY). The use, distribution or reproduction in other forums is permitted, provided the original author(s) and the copyright owner(s) are credited and that the original publication in this journal is cited, in accordance with accepted academic practice. No use, distribution or reproduction is permitted which does not comply with these terms. 